\title{
CASE REPORT ON EPIDERMOLYSIS BULLOSA- A RARE DISORDERS
}

\author{
Dileepreddy Gottimuukula ${ }^{1}$, Rakesh Chakinala ${ }^{1}$,Surender Kagithapu $^{2}$,Yogi Morishetty ${ }^{2}$, Goverdhan \\ Puchchakayala $^{1^{*}}$. \\ ${ }^{1}$.Department of Clinical Pharmacy, VaagdeviCollege of Pharmacy, Ramnagar, Hanamkonda \\ ${ }^{2}$.KakathiyaMedical College, Mahathma Gandhi Memorial Hospital, Warangal, Telangana \\ * Corresponding Author: Dr. Goverdhan Puchchakayala \\ Professor \& Head, \\ Department of Clinical Pharmacy, \\ Vaagdevi College of Pharmacy, \\ Warangal, Telangana State, India. \\ Ph.no: $+91-9440853948$. \\ Email: gov ku@yahoo.co.in. \\ www.vaagdevipharmacy.com
}

\begin{abstract}
:
Epidermolysisbullosa is a rare group of skin disorders which is characterized by extreme fragility of skin and mucous memberane, which leads to formation of blisters and skin lesions. It affects 1 out of every 50,000 live births. There is no specific treatment, daily wound care and pain management are the only available treatment options. Here we report a case of male neonate with epidermolysisbullosaand respiratory distress. The neonate was died due to severe respiratory distress.
\end{abstract}

KEY WORDS: Epidermolysisbullosa,blisters, lesions, respiratory distress.

\section{INTRODUCTION:}

Epidermolysisbullosa (EB) is a congenital defect in the skin structure and is often heterogeneous group ofhereditary disorders which is characterized by extreme fragility of skin and mucous membranes, which gives rise to formation of blisters and ulcers following minor trauma ${ }^{(1)}$.There are 3 types of EB they are classified based on the level at which the tissue separates and the blisters form i.e, depending on whether this happens above, within, or below the epidermal basement memberane.

1.Epidermolysisbullosa simplex (EBS-intraepidermal skin separation).

2.Junctionalepidermolysisbullosa(JEB-skin separation on lamina lucida)

3.dystrophicepidermolysisbullosa(DEB-sub lamina separation).

Among these EBS is the most common one ${ }^{(2),(3)}$. The incidence of EB estimated by a National EB Registry report 50 cases per million live births, of these cases approximately $92 \%$ will be EBS, $5 \%$ DEB, $1 \%$ JEB, and $2 \%$ unclassified $^{(4)}$. The disease is always painful, is often pervasive and unbearable. The neonates born with it are often called "Butterfly Children" because as the resemblance of their skin is as fragile as the wings of a butterfly. There is no treatment, daily wound care, pain management and protective bandaging are the only available treatment.

\section{CASE REPORT:}

A full term male neonatewas admitted to hospital with the complaints of blistering of the skin since birth involving both lower limbs, cheek, left elbow, back, respiratory distress, lower limb deformity and birth asphyxia (Figure 1). His birth weight was $2.0 \mathrm{kgs}$. The baby was born to a 22 years lady who was married at the age of 17 years. There was a history of Consanguinity marriage of their parents. There was no family history of bullous skin lesions. On physical examination respiratory rate is $-46 / \mathrm{min}$, Pulse rate $-112 / \mathrm{min}$, Cvs-normal, per abdomen - soft, $\mathrm{Spo}_{2}-100 \%$. The investigation advised are $\mathrm{CBP}$ (complete blood picture)with platelet count, $\mathrm{CRP}(\mathrm{C}$ - Reactive protein), Chest Xray. The treatmentgiven on the day of admission are:

1. Warmth care on mechanical ventilator.

2. I.V. Fluids $10 \%$ Dextrose $40 \mathrm{ml} / \mathrm{IV} / \mathrm{QID}$.

3. Inj. Ampoxin 100mg/IV/BID.

4. Inj. Cefotaxime $100 \mathrm{mg} / \mathrm{IV} / \mathrm{BI}$

5. Inj.Dopamine $15 \mathrm{mg}$ in $10 \mathrm{cc}$ Normal saline @ 0.8ml/hr.

6. Fusidine ointment.

7. Skin care.

Subsequently, 2 days the infant was died due to severe respiratory distress. 


\section{ISSN $2393-9257$ \\ Volume $3 \mathrm{Number} 3$ \\ Journal of Advances in Natural Sciences}

\section{DISCUSSION:}

Epidermolysisbullosa is a group of inherited disorders which involve the formation of blisters following minor trauma. Over 300 mutations have been idientified in EB. These disorders represent heterogeneous phenotypes and are connected with a variable range of complications, from localized skin fragility to neonatal mortality ${ }^{(5)}$.

EB are classified in to three types of genetically inherited, they are simplex, Dystrophic and Junctional. These three types are differ phenotypically and genotypically. Three major phenotypes have been described depending on the level of cleavage of the basement memberane at dermoepidermal junction, the level of separation in EBS is intraepidermal and lamina densa in junctional EB.In dystropic EB the separation is below the basement memberane ${ }^{(5),(6)}$. The three phenotypes have both autosomal dominant and autosomal recessive form of inheritance.

A wide range of genetic abnormalities occur in various types of EB. $K_{5}$ or $K_{14}$ gene mutations results in bullosa formation by disrupting the basal cells in dominant simplex as well as some forms of recessive EB simplex. In junctional EB type XVII collagen, laminin 5 anda6, $\beta 4$ integrin gene mutations are involved. In dystrophic variant is linked with type VII collagen gene abnormalities ${ }^{(7) \text {. }}$

In EBS blisters are usually present at birth or during neonatal period. Sites of predilection are the hands, feet, knees, legs and scalp ${ }^{(2),(8)}$ where as the intraoral lesions are minimal. Nails rarelybecome dystrophic and usually regrow even when they are shed. EBS blisters typically heal with minimal to no scar or milia formation and do not result in skin atrophy ${ }^{(2),(8)}$. Secondary infection is the primary complication. The tendency to blisters decreases with age, and long term prognosis is good. Blisters should be drained by puncturing, but the blisters top should be left together to protect the underlying skin ${ }^{(2)}$. When the child begins to walk localized EBS of the hands and feetare often presents; onset may be delayed, until puberty or early adulthood when heavy shoes are worn or feet are subjected to increased trauma. Bullae are restricted to hands and feet ${ }^{(2),(9),(10)}$; rarely, they occur at dorsal aspects of the arms and shins.

\section{CONCLUSION:}

At present there is no definiteand curative treatment for EB. Hence the aim of the treatment is alleviate symptoms, supportive and preventive measures ${ }^{(11) .}$ Therapy is therefore focused on the prevention of lesions and complication. The successful management is expert nursing care. Nursing the babies on thick foam padsthem from undue trauma induced blistering. Topical antibiotics are avoided because of the risk of emergence of antibiotic resistant bacteria. Soft, nonadhesive dressing materials soaked with emollients such as vaseline were used as a preventive measure. Parents were counseled and psychological support was given to them, which plays a major role in the care oftheseneonates ${ }^{(11)}$. Nutritional support is important for adequate growth and development and promote wound healing.

\section{REFERENCES}

1. Uitto J, Pulkkinen L. 2000. EpidermolysisBulossa in Mexico. Int J Dermatol., 433-435.

2 .Morelli JG. 2007. Vesiculobullous disorders. In Nelson Text book of paediatrics. 18th edition, Philadelphia, Pennsylvania, Saunders: 2685-2693.

3. Cooper TW, Bauer EA. 1984.Epidermolysisbullosa: A Review. PeadiatrDermatol., 1:181-188.

4. Fine JD, Bauer EA, Gedde-Dahl T.1999. Inherited epidermolysisbullosa: definition and historical overview.In: Fine JD, Bauer EA, McGuire J, eds. EpidermolysisBullosa: Clinical, Epidemologic, and Laboratory Advances and the findings of the National EpidermolysisBullosa Registry. Baltimore: Johns Hopkins University press, 1-19.

5. Fine JD, Johnson LB, Suchindran C, Moshell A, Gedde-Dahl T Jr. 1999. The epidemiologyof Inherited EpidermolysisBullosa: Findings in the US, Canadian and European study populations. In Fine JD; Bauer EA, McGuire J, Moshell A editors; Clinical, epidemiological and laboratory advances, and the findings of the national epidermolysisbullosa registry. Baltimore: John's Hopkings university press, 101-113.

6 .Pulkkinen L, Uttio J.1999 feb18(1). Mutataion analysis and molecular genetics of epidermolysisbullosa. Matrix Biol, 2942.

7.Mitsuhashi Y, Hashimoto I. 2003. Genetic abnormalities and clinical classificationsof epidermolysisbullosa. Arch Dermatol Res 2003 Apr;295Suppl 1:S29-33.

8.Featherstone C. 2007. Epidermolysisbullosa: from fundamental molecular biology to clinical therapies. J Invest Dermatol., 127: 256-259.

9.Fine JD, Eady RA, Bauer EA, Bauer JW, Bruckner-Tuderman L, Heagerty A et al..2008. The classification of inherited epidermolysisbullosa (EB): Report of the Third International Consensus Meeting on Diagnosis and Classification of EB. J AM AcadDermatol., 58(6):931-950.

10.De Kanter K. 2004. Epidermolysisbullosa simplex: localized (Weber-Cockayne type). Dermatol Nurs.,16: 525.

11.Purushotham DR, SunilB, Aadarsh E, RajanishKV, Tamilselvan, KarthikArigela. 2014. Epidermolysisbullosa in newborn: A case report.Scholars journal of applied medical sciences2014;(1B):149-51. 
Journal of Advances in Natural Sciences

Figure 1: Showing blistering of the skin since birth involving both lower limbs, cheek, left elbow, back,inepidermolysisbullosa.
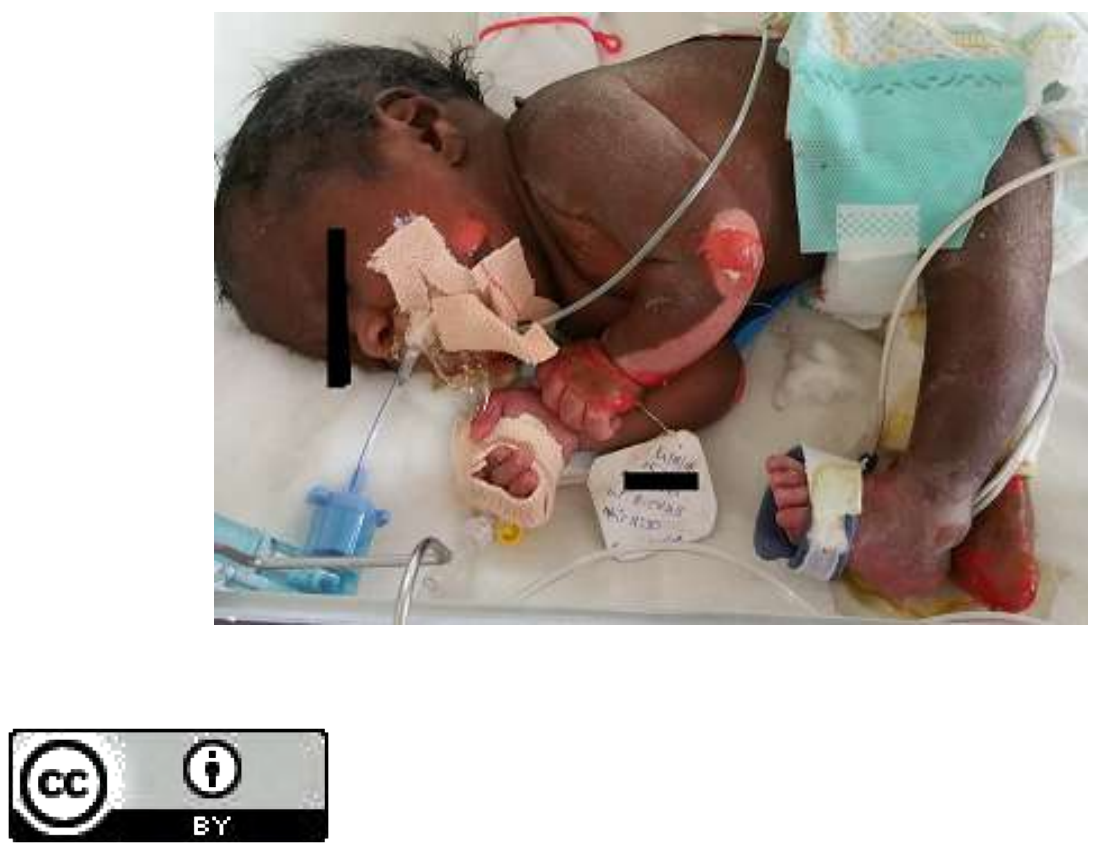

This work is licensed under a Creative Commons Attribution 4.0 International License.

D O I : $10.24297 /$ jns.v3i3.5008 